\title{
Taking Specialist Surgical Services to the Rural District Hospitals at One Forth Cost: A Sustainable 'Return on Investment' Public Health Initiative of Patan Hospital, Patan Academy of Health Sciences, Nepal.
} Shah JN

Department of Surgery

Patan Hospital, Patan Academy of Health Sciences,

Patan, Nepal.

\section{Corresponding Author}

Jay N Shah

Department of Surgery

Patan Hospital, Patan Academy of Health Sciences,

Patan, Nepal.

E-mail: drjaywufei@hotmail.com

\section{Citation}

Shah JN. Taking Specialist Surgical Services to the Rural District Hospitals at One Forth Cost: A Sustainable 'Return on Investment' Public Health Initiative of Patan Hospital, Patan Academy of Health Sciences, Nepal. Kathmandu Univ Med J 2015;50(2):186-92.

\begin{abstract}
The inequitable distribution and centralization of resources and services in urban area persists around the world, more so in developing countries. The challenge to meet the health needs of rural population requires health policy makers, government and concerned organization to put extra efforts. Such efforts require innovative, feasible and sustainable strategies to address the social justice of people living in districts away from capital and urban cities. At Patan Academy of Health Sciences, the medial school curriculum is designed to address these issues. Together with health professionals from Patan Hospital, the main teaching hospital on which the academy evolved, have initiated strategies to bring specialist services, starting with surgical services to remote district hospitals to serve the need of rural population. This initiative is 'desirable, doable and feasible'. Further more, this can be modified for replication and promotion by other academic institutions, central hospitals and government health system.
\end{abstract}

\section{KEY WORDS}

District hospital, public health, return on investment, rural Nepal, specialist service, surgery.

\section{INTRODUCTION}

Health policy makers around the world face challenges to meet the needs and narrow down the gaps between urban and rural health services. The World Health Organization recognizes the challenges of the shortages of human resource for health $(\mathrm{HRH})$, uneven distribution, brain drain and chronic undersupply of $\mathrm{HRH}$ in rural areas. ${ }^{1}$ Besides availability of $\mathrm{HRH}$, economic and geographical barrier are important consideration in both developing and developed countries. Nepal is not exception to it.

Policy makers internationally and locally have failed to recognize and include 'essential surgeries and safe anesthesia' (ESASA) as part of comprehensive public health service strategies to decrease the morbidity and mortality, ${ }^{2,3}$ especially for rural and marginalized populations in 'low and middle income' countries (LMIC) like Nepal. ${ }^{4}$ The Global Burden of Surgical Disease Working Group (BoSDWG) comprised of multidisciplinary professionals of physicians, economists, epidemiologists, public health specialists, academicians, not-for profit humanitarian organization and WHO has been active since 2008. ${ }^{5}$ The BoSDWG has been engaged in research, training, and delivery of surgical services in LMICs to maximize the role of surgical care to address health care disparities. The 'perception' that surgical service is 'costly, resource intensive, require highly trained specialized manpower and benefit less number of population' is not true in view of refuting evidences. ${ }^{5-7}$ There is increasing global interest to address the need of 
surgical services in developing countries, for e.g. the WHO Global Initiative on Emergency and Essential Surgical Care to promote universal access of essential surgery and safe anesthesia in LMICs. On policy level, the WHO Integrated Management for Emergency and Essential Surgery toolkit provides guidance on policies, training technologies, and research focused on health systems strengthening through primary health care. ${ }^{8}$ The WHO 'Safe Surgery Saves Lives' initiative works to review and promote policies, personnel, and equipment to improve patient safety. ${ }^{6,9}$

The MDGs do not to directly mention surgical care as a component of global health care. ${ }^{10,11}$ The LMICs have one-third of global population, but they have only $3.5-5 \%$ surgical services performed globally. ${ }^{12}$ The 'insufficient, inequitable distributions' of resources in district hospital (DH) needs to be addressed to make 'ESASA' accessible to rural population. ${ }^{13,14}$ The observation of 'operative capabilities of $78 \mathrm{DH}$ in seven LMICs 'Bangladesh, Bolivia, Ethiopia, Liberia, Nicaragua, Rwanda, and Uganda' revealed alarming situation of "one surgeons and anesthetists serving up to 100,000 to one million population; inadequate infrastructure, and shortages of essential equipment". ${ }^{15}$ We in Nepal need to take into account this observation to make strategies to improve our health system and service deliveries to better serve needy people.

\section{Nepal health care system}

The Government of Nepal has put remarkable efforts in producing $\mathrm{HRH}$ both in public and private sector. ${ }^{16}$ However, the health services are mostly concentrated in the urban centers with $19 \%$ of population, whereas $81 \%$ of the population residing in rural Nepal may not have easily accessible health services. ${ }^{17}$ Even after the new national health policy (NHP) 1991, the utilization of health facilities were limited because of accessibility. The primary health care outreach (PHC/ORC) services were initiated that served 132,000 to 150,000 individuals yearly in Fiscal year 2067-68 (2010-11) through 2069-70 (2012-13). ${ }^{18}$ However, the recent Annual Report of Department of Health Services (DHS) has not revealed if there were any specialist surgical services offered. Nepal has vast geographic diversity. There is less than 100 meters ( $328 \mathrm{ft}$.) elevation in the tropical Terai to some 90 peaks over 7,000 meters $(22,966 \mathrm{ft}$.) including worlds highest 8,848 meters $(29,029 \mathrm{ft}$.), the Mount Everest (Sagarmatha). There are three distinct geographical regions in Nepal, the Terai, Hill and Mountain. ${ }^{19}$ Thus, in a country like Nepal, outreach specialist surgical services can maximize the impact of health expenditure and outcome, to address the inaccessible and inequitable health services. Nepal government has been trying to provide basic health services to her population (http://dohs.gov.np/planpolicies/). However, it is still 'out of pocket' payment health system, which puts tremendous burden to the average Nepali with 'a dollar a day' income.

Benefit of specialist services delivery, especially the 'procedure' based services to the people in rural districts is a blessing as they are unable to access such services from the static urban centers due to 'cost, time, distance'.

\section{PAHS Initiative}

Patan Academy of Health Science (PAHS) is dedicated to improve the health status of the people of Nepal by producing competent HRHs, who are willing and able to provide health care in disadvantaged rural areas. ${ }^{20}$ In addition, as envisioned by the NHP, it supports the objectives of bringing the health service to rural population.

General 'health camps' in resource poor rural environment are at best limited to public awareness unless they are supported by periodic specialist backup. At PAHS, a quarter of five years of undergraduate medical school MBBS (Bachelor of Medicine, Bachelor of Surgery) curriculum is dedicated to "Community based Learning and Education" (CBLE). It focuses on value-based curriculum with emphasis on community health sciences (CHS) and exposure to rural health care institutions of Ministry of Health and Population (MOHP) Nepal. To experience 'step-wise scaledup' exposure to national health system (NHS), the medical students start with urban slum posting, moving up to village and 'staying with local families' doing their community based participatory project works in coordination with health posts (HP) and district public health officers (DPHO), and finally six months residential posting during final school year at one of the four teaching district hospitals (DH) of PAHS. ${ }^{21}$ (Fig. 1).

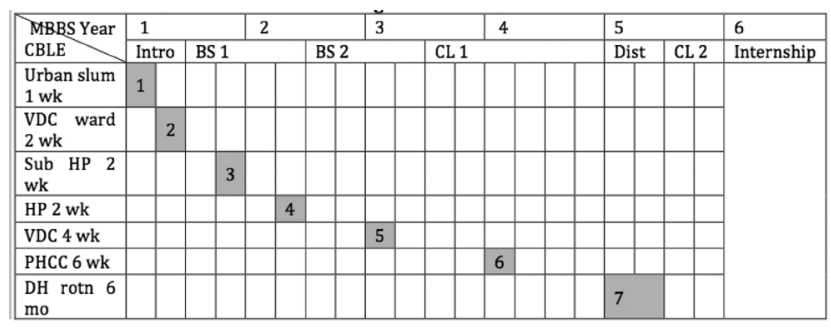

Figure 1. CBLE Scheme under CHS for undergraduate MBBS curriculum of SOM-PAHS.

Note: CBLE- Community Based Learning and Education, CHS- community health science, MBBS- Bachelor of Medicine, Bachelor of Surgery, SOMPAHS- School of Medicine Patan Academy of Health Sciences, Introintroduction to clinic medicine, BS- basic science, CL- clinical science, Dist- district, VDC- village development committee, wk- week, mo- month, HP- health post, PHCC- primary health care center, DH rotn- District hospital rotation (students are divided in two groups, $1^{\text {st }}$ group is further subdivided to cover four $\mathrm{DH}$ for six months and then $2^{\text {nd }}$ group replaces them to have presence of final year students in $\mathrm{DH}$ throughout the year)

PAHS has already collaborated with four district level government hospitals to cover terai and hills (Gorkha DH, Trishuli Hospital in Nuwakot District and Nawalparasi DH) and Am Pipal Hospital in Gorkha (Fig. 2). Besides teaching learning activities, PAHS aim to have continuous presence of final year medical students and faculties for five years or more to bring out visible changes in health indicators in these districts. The provision of residential general practice family physician (GP) as preceptor and service provider is 
having positive impact. For this purpose, the MOHP need to support PAHS enthusiastically for continuous presence and involvement in the community and districts health services.

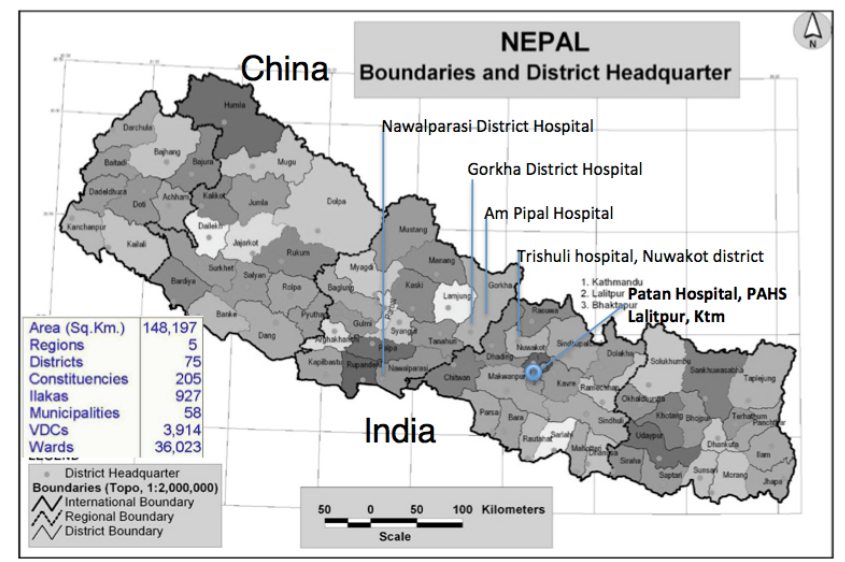

Figure 2. Four partner district hospitals PAHS has collaborated with for year round residential posting of final year medical students. (Map of Nepal showing districts to VDCs - http:// Igcdp.gov.np/home/map-center.php)

Additionally, all four $\mathrm{DH}$ have functional, on-going real time link-up for 'classes and discussions' via 'virtual classroom' tele-link with $\mathrm{PH}, \mathrm{PAHS}$. Furthermore, they can use this facility to be in touch among themselves too. Also, the provision of periodic specialized health camps (beginning with surgery) provides free services to benefit the patients and help to upgrade the skills of local HRHs.

As piloting, PAHS did start specialized surgical camps at Gorkha DH. Even though hospital was recently upgraded to 50 beds, it provides limited surgical service e.g. caesarian section depending on the availability of GP or gynecologist. The operation theater is reasonably functional with anesthesia machine, monitor etc., but no general anesthesia (GA) service is provided due to unavailability of anesthetist. (Fig. 3)

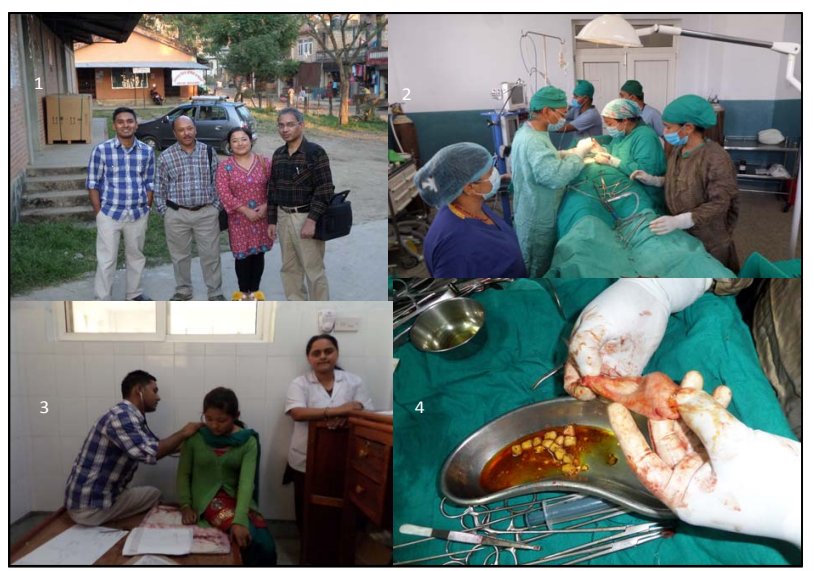

Figure 3. Image from the surgical service camps at Gorkha, 1. Dr Anil Shrestha, Dr Rajesh Gongal, Sr Rupa Maharjan, Dr Jay Shah (author) 2. Reasonably functional Operation Theater 3. Pre-operative anesthetic check-up 4. Inspecting gallbladder specimen, thin wall with normal looking mucosa were not routinely sent to Kathmandu for histopathology.

\section{A. Stepwise overview of the initiative of free surgical camp}

The $\mathrm{DH}$ published prior notice via local newspaper and radio about the specialist surgical camp in collaboration with $\mathrm{PH}$, PAHS. After about 6 hours drive from Kathmandu (Ktm), we reached Gorkha and started consultation for 60 registered patients, mostly with gallstones. Seven symptomatic gallstone patients, three children with inguinal hernia, one adult hernia and two large scrotal hydroceles were selected for surgery. Asymptomatic gallstone patients were counseled that they did not need surgery for incidentally found gallstones on ultrasonography (USG). In case of pain they could visit $\mathrm{DH}$ and transferred to $\mathrm{PH} / \mathrm{PAHS}$ for preferential schedule of surgery. The patients with comorbidities and possibility of common bile duct (CBD) stones (even if we were prepared with T-tube), jaundice, unstable diabetes or hypertension and conditions that could demand additional intensive care were advised to visit $\mathrm{PH} /$ PAHS or other appropriate hospitals of their choice. Chest $X$-ray, electrocardiogram, blood grouping, hemoglobin $(\mathrm{Hb})$, serum creatinine and urine routine were obtained as needed. Local Red Cross was alerted for possible need of blood transfusion from volunteer 'walking blood bank'. We met hospital administrator, operation theater staff and anesthetist assistant (AA) on same evening for logistics preparation. The AA are paramedics with six months to one year training to assist anesthetist. But in districts, they are sole provider of local and spinal anesthesia, even GA in some places.

Next morning surgery began at 8:00 and completed six cholecystectomies and two herniotomies by evening. On the $2^{\text {nd }}$ day, we split our team. One team consisting of surgeon, anesthetist and nurse stayed back to continue with the remaining cases on day two. This team returned to Ktm by late afternoon after completing the surgeries and being assured that all patients were stable. Medical officer and GP were briefed to continue with general management and follow up. Another team, comprising of author and administrator from PAHS departed for Lamjung to route through Parbat and Mayagdi DHs in rural districts to explore for possible partnership for PAHS medical curriculum. After whole day drive we arrived at 7:00 PM to meet the district public health officer in Lamjung as planned. In morning after brief hospital visit and meeting the local development officer, we left for Parbat and Myagdi in remote hills. After 6 hours drive from Lamjung we arrived late afternoon to meet with the GP of Parbat DH as planned. We returned to hotel at 9:30 pm to unpack and get rest to continue early next morning for Mayagdi. However, at $10 \mathrm{pm}$ we got call from Dr. Gongal, the surgeon who had arrived in Ktm from Gorkha. He had message from nurses and GP in Gorkha that a cholecystectomy patient was pale, $\mathrm{Hb}$ had dropped to 9 from $13 \mathrm{~g} \%$. He tried to console us that patient's was ok and I (the author) could rest the night at Parbat itself and return to Gorkha in the morning, instead of heading to Mayagdi. 
However, we felt it was not wise to wait till next morning. On the other hand, it was a difficult decision to drive through tortuous mountain road at midnight. Our driver also felt the seriousness of situation and was truly generous and confident despite being on road whole day. We departed at 11 PM paying for the hotel rooms we did not use! On the way we stopped at roadside tea shops, wherever we could find one to have a break for the tired driver. Finally, we arrived in postoperative ward by 4:30 AM. The nurses were asking surprisingly "Dr. you got up so early'! They were genuinely appreciative knowing we drove whole night from Parbat.

Together with AA and GP Dr. Yogendra Amatya, we assessed the patient. She was stable with soft abdomen. Blood was sent for repeat $\mathrm{Hb}$, volunteer blood donors and Red Cross were alerted. We returned to the hotel where staffs were equally surprised to see their earlier guests arrive at $5 \mathrm{AM}$ asking for rooms. In mean time, the nurse called that $\mathrm{Hb}$ was holding at $8.8 \mathrm{~g} \%$. We could relax for a while. At 9 AM we walked back to the hospital. Patient looked fresh, re$\mathrm{Hb}$ was $8.6 \mathrm{~g} \%$. Soft diet was started keeping the IV line for safety. We stayed overnight for further assurance. Next morning, the patient looked stable and fresh with re-Hb holding at $9 \mathrm{~g} \%$. We resumed our journey to Mayagdi.

During $2^{\text {nd }}$ camp at Gorkah DH after 5 months, we modified our plan and stayed back one more day 'after' surgery. Only minor cases under local anesthesia were scheduled for $3^{\text {rd }}$ day before we returned to Ktm. However, the first cholecystectomy patient developed abdomen pain and distension on $1^{\text {st }}$ day of surgery. The tube drain was dry. It was kept during surgery for bile leak from gall bladder bed that was sutured adequately. The GP did not find significant free fluid on abdomen USG. We explained to the patient and her husband about possibility of bile leak and needed to stick needle to confirm before re-surgery if needed.

I volunteered to tap the right iliac fossa (RIF), thinking Dr Gongal being operating surgeon and GP who had performed USG, could feel extra pressure in the circumstances. Bilious fluid from RIF was tapped. The patient and her husband were explained of options to wait and watch or re-surgery to fix the problem of bile leak in Gorkha itself with placement of T-tube if necessary. They consented for re-surgery. There was no obvious injury to $C B D$, cystic duct tie was intact and no leaking bile ducts from gall bladder bed. We went ahead with putting T-tube in CBD through cystic duct. Postoperative recovery was uneventful. Oral liquid was started on $1^{\text {st }}$ day. The GP was advised for T-tube cholangiogram after 3 weeks. He transferred the image by mobile phone. It was normal. The T-tube was removed later at five weeks.

\section{B. Cost effectiveness and 'return on investment}

The contribution from $\mathrm{PH}, \mathrm{PAHS}$ through the outreach surgical services from university teaching hospital is a model initiative to serve rural population in the districts. This saves patient's travel to alien urban centers, saves time, money and anxiety of leaving home. In the absence of PAHS outreach surgical services they needed to travel to Ktm or elsewhere for consultation and surgery. Here, we would like to appraise approximate financial benefit a patient could obtain from each rupee they spend on health care need.

\section{B1. Direct cost to PAHS incurred during surgical camp}

The team for free surgical camp consisted of two drivers for two vehicles, two Consultant Surgeons (both Prof level, the author was then Vice-Chancellor and Rajesh Gongal, the Dean), one each of anesthetist, operation theatre (OT) nurse and administrator. It was two nights three days camp. Total cost of camp born by PAHS was NRs. 155,700 (Table 1). One USD equals approximately $100 \mathrm{NRs.}$

Table 1. Contribution of PH, PAHS for specialist surgical services at Gorkha DH

\begin{tabular}{|c|c|c|c|}
\hline No. & Particulars & & $\begin{array}{l}\text { Cost } \\
\text { NRs. }\end{array}$ \\
\hline 1 & Remunerations $^{1}$ & 7 person $\times 3$ days $=21$ days & 60,000 \\
\hline 2 & Hotel accommodation ${ }^{2}$ & $\begin{array}{l}7 \text { person } \times 2 \text { nights } \times \text { Rs. } \\
1200 \text { a night }(7 \times 2 \times 1200)\end{array}$ & 16,800 \\
\hline 3 & Food $^{1}$ & $\begin{array}{l}7 \text { person } \times 3 \text { meals } \times \text { Rs. } \\
300 \times 3 \text { days }(7 \times 3 \times 300 \times 3)\end{array}$ & 18,900 \\
\hline \multirow[t]{2}{*}{4} & Vehicle & $\begin{array}{l}2 \text { vehicles } \times 3 \text { days } \times 10,000 \\
\text { a day }(2 \times 3 \times 10,000)\end{array}$ & 60,000 \\
\hline & & Total & 155,700 \\
\hline
\end{tabular}

Note: PH- Patan Hospital, PAHS- Patan Academy of Health Sciences, DHDistrict Hospital, NRs- Nepali Rupees. ${ }^{1}$ Rmuneration is an approximate figure based on monthly (at 5 working days per week, 21 days equivalent to one month) salary of staff at PH, PAHS, ranging from NRs 16,000 to 70,0000 per month. ${ }^{2}$ From $2^{\text {nd }}$ camp we modified our plan to stay one day extra after major surgeries, i.e. 3 nights 4 days.

\section{B2. Projected cost if patients travel to Ktm for consultation and surgery}

Generally, the patients are seen in outpatient clinics, investigated and given later date to come for surgery. The waiting time could be from one month to one year in government hospitals, in average its 2 to 3 months at $\mathrm{PH}$. If patients had to travel to Ktm for consultation and surgeries, the cost could be substantial. Direct cost approximately NRs 312,000 for consultation (Table 2) and NRs 410,000 for surgeries (Table 3), total NRs. 722,000. This calculation is based on ideal situation when patients travel smoothly by road, get to see surgeons on time, finishes all the investigations, get date for surgery and return home next day. Usually this takes longer adding to the cost and dilemma of the patients and accompanying family members as well as situation back home.

\section{DISCUSSION}

We encountered manageable challenges in taking specialist surgical services to the rural $\mathrm{DH}$. The local people benefitted from this initiation from $\mathrm{PH}, \mathrm{PAHS}$ with substantial savings 
Table 2. Cost estimation if patients had to travel to Ktm for consultation provided at Gorkha DH

\begin{tabular}{|c|c|c|c|}
\hline No. & Particulars & & $\begin{array}{l}\text { Cost } \\
\text { NRs. }\end{array}$ \\
\hline 1 & Travel $^{1}$ & $\begin{array}{l}60 \text { patients } \times 2 \text { accompanying family } \\
\text { members ( } 180 \text { persons) } \times 2 \text { ways travel } \\
\times \text { Rs. } 400 \text { bus fare }(33 \times 2 \times 400)\end{array}$ & 144,000 \\
\hline 2 & Food & $\begin{array}{l}60 \text { patients } \times 2 \text { family members ( } 180 \\
\text { persons) } \times \text { Rs. } 200 \text { a meal } \times 3 \text { meals a } \\
\text { day } \times 2 \text { days }(180 \times 200 \times 3 \times 2)\end{array}$ & 216,000 \\
\hline 3 & Hotel & $\begin{array}{l}60 \text { patients with family members share } \\
\text { one room } x \text { one night } x \text { Rs. } 1,000(60 x \\
1 \times 1,000)\end{array}$ & 60,000 \\
\hline 4 & $\begin{array}{l}\text { Local } \\
\text { Transport }^{2}\end{array}$ & $\begin{array}{l}60 \text { patients with } 2 \text { family members ( } 180 \\
\text { persons) x Rs. } 252 \text { ways } \times 2 \text { days ( } 180 \\
\times 25 \times 2 \times 2 \text { ) }\end{array}$ & 18,000 \\
\hline
\end{tabular}

Note: ${ }^{1}$ Visit surgeons for consultation in Ktm, 60 patients with two accompanying family members, total 180 persons require to travel to Ktm.

${ }^{2}$ Local transport is based on minimum cost of public transport in Ktm, however for patients and being in big urban cities, taxi is often the need which cost 20 times more.

Table 3. Cost estimation if patients had to travel to Ktm for surgeries provided at Gorkha DH

\begin{tabular}{|c|c|c|c|}
\hline No. & Particulars & & $\begin{array}{l}\text { Cost } \\
\text { NRs. }\end{array}$ \\
\hline 1 & Travel1 & $\begin{array}{l}11 \text { patients }+22 \text { family members, } 2 \\
\text { way travel, Rs. } 400 \text { one way bus fare } \\
(33 \times 2 \times 400)\end{array}$ & 26,400 \\
\hline 2 & Food1 & $\begin{array}{l}11 \text { patients }+2 \text { family members, Rs. } \\
200 \text { per meal } \times 3 \text { meals per day x } 6 \\
\text { days }(33 \times 2 \times 200 \times 3 \times 600)\end{array}$ & 118,800 \\
\hline 3 & Hotel1 & $\begin{array}{l}\text { Patients in hosp, family in shared hotel } \\
\text { rooms, } 11 \text { rooms } \times 5 \text { nights } \times \text { Rs. } 800 \\
\text { per night per room ( } 11 \times 5 \times 800)\end{array}$ & 44,000 \\
\hline 4 & $\begin{array}{l}\text { Local } \\
\text { Transport }{ }^{2}\end{array}$ & $\begin{array}{l}\text { Patients in hosp, } 22 \text { family members } x \\
\text { Rs. } 25 \times 2 \text { way public transport } \times 6 \text { days } \\
(22 \times 25 \times 2 \times 6)\end{array}$ & 6,600 \\
\hline 5 & Surgeries $^{3}$ & $\begin{array}{l}7 \text { cholecystectomies Rs. } 25,000 \text { each }+ \\
4 \text { hernias Rs. } 10000 \text { each }(7 \times 25,000+ \\
4 \times 10,000)\end{array}$ & 215,000 \\
\hline
\end{tabular}

Total 410,000

Note: ${ }^{1}$ Two-accompanying persons for 11 surgeries ( 7 cholecystectomy +4 hernia/hydrocele) require 33 persons to travel to Ktm. Many a times patients require ambulance or air travel which costs at least 20 times more.

${ }^{2}$ Local transport is based on minimum cost of public transport in Ktm. In urban cities and for patients often taxi is needed, could cost 20 times more.

${ }^{3}$ The surgery cost is total (operation, investigation, supplies, bed) in government hospital, in private will cost up to 5 times more.

in direct cost. The contribution from PAHS of approximately NRs 155,700 in one surgical camp generated savings of NRs 722,000 for patients if they had to travel to Ktm for same services. There were some costs to patients at $\mathrm{DH}$ too, for example, opd ticket, medicines, food, local travel etc. These are nowhere near to the costs, hassles, and anxiety if they had to leave home and travel to Ktm or other urban centers.
Leaving home for urban city for surgery have much greater consequences than cost itself, for example, whom to leave the responsibility of taking care of children and elderly at home, managing agriculture lands, cattle, shops etc. The anxiety and feeling lost in big cities are important consideration. There could be many patients staying back home without treatment due to financial, geographical and social limitations. The outreach strategy addresses these issues fulfilling the demand of health care for community in rural districts.

Three decades ago, it was unheard of private hospitals in Nepal. But, it got mushrooming after new NHP in 1991. In last three decades population in Ktm valley has grown almost ten folds reaching five million but there has been no increase in the number of government hospitals to serve the growing population. The unmet healthcare need combined with inadequate poor service and poor controlling mechanism of government institutions gave opportunities to private enterprises stationed in urban areas to expand their capacity and draw profits. Exact number is higher today, but as per MOHP and Association of Private Health Institution of Nepal (APHIN), two years ago, there were 366 private hospitals in Nepal among which 99 are in the Kathmandu Valley, in comparison to 123 government hospitals across whole Nepal. ${ }^{22}$ Medical facilities and affordability of the private hospitals are 'compulsion' rather than 'choice' for most of the people.

Doctors registered with Nepal Medical Council has reached 15,640 by mid April 2015 as per council secretariat (office telephone 977-1-4377164). ${ }^{23}$ Estimated one third has 'brain drained' out of Nepal to affluent countries and majority of remaining stay in urban cities like Ktm, Chitwon, Pokhara etc. In 2013-14 MOHP 'department of health service' sanctioned 466 doctors post for 75 districts but only 258 posts were fulfilled. ${ }^{24}$ This scenario speaks for itself.

Essential surgery and safe anesthesia services is an important part of a comprehensive global health, but the policy makers in LMICs have not given due attention and should be reflected in Post-2015 Development Agenda to address the burden of surgical disease as an important contributor to premature disability and death. Survey of operative capacities of 78 government DHs in seven LMIC (Bangladesh, Bolivia, Ethiopia, Liberia, Nicaragua, Rwanda, and Uganda) revealed that $70 \mathrm{DHs}$ had fewer than one surgeon or anesthetist to serve 100,000 populations. The service of operative procedures fell short of the need because of limited capacity of infrastructure as well as HRHs. ${ }^{15}$ Nepal is no exception.

Productions of doctors have increased many folds due to newly established private medical colleges, but social accountability part is lacking from majority of stakeholders in Nepal. The 'public private partnership' could be a way forward. ${ }^{25}$ The initiative by PAHS to take specialist services to rural districts is a model strategy to serve deprived population, to draw attention of MOHP and health system 
planner to support, promote and include this as national health policy. This program can be 'institutionalized' through academic institutions and central hospitals. In future, as system matures it is possible to manage the camps by academia and central hospital 3-monthly with their own HRHs (a surgeon, nurse, anesthetist). The cost of the camp could be higher for private parties or NGOs who need to contract (hire) experts (surgeons, anesthetist, nurse etc).

\section{CONCLUSION}

The academic programs together with services to rural districts from PAHS will have a positive and long-term influence of cost effective way for outreach specialist health service delivery. The academia, medical colleges and government need to have built-in strategies with necessary budget. We need to work together to institutionalize this initiative of effective and sustainable 'return on investment' for equitable, socially justifiable health services to the unreached rural population in districts of Nepal.

\section{ACKNOWLEDGEMENT}

I would heartily thank the AA and local staffs, the chairman of hospital development board of Gorkha DH, and the OT nurse Rupa Maharjan, anesthetists Dr Anil Shrestha and Sirish Amatya for their team-sprit. Rajesh Gongal, the Prof. of surgery and dean for being excellent partner and Mr KB Bhandari the administrator from PAHS for logistics. Drivers Mr Dev and Bachhu Adhikari for safely driving us in difficult times. Thanks to the patients and their families for entrusting us to serve them by starting major surgical services under GA in their DH. Finally, sincere thanks to Prof. RK Dulal for inputs in final manuscript.

\section{REFERENCES}

1. Eric de Roodenbeke, Sev Lucas, Aurélie Rouzaut, Fidèle Bana. Outreach services as a strategy to increase access to health workers in remote and rural areas. http://www.who.int/hrh/resources/ outreach/en/

2. Ozgediz D, Dunbar P, Mock C, Cherion M, Rogers SO Jr, Riviello R, Meara JG, Jamison D, Macfarlane SB, Burkle F Jr,McQueen K. Bridging the gap between public health and surgery: Access to surgical care in low- and middle-income countries. Bull Am Coll Surg. 2009 May;94(5):14-20.

3. Debas H, Gosselin R, McCord C, et al. Surgery. In: Jamison DT, Breman J, Measham AR, et al, eds. Disease Control Priorities in Developing Countries. New York: Oxford University Press; 2006.

4. Gosselin RA, Heitto M. Cost-effectiveness of a district trauma hospital in Battambang, Cambodia. World J Surg. 2008;32(11):2450-3.

5. Spiegel DA, Gosselin RA. Surgical services in low-income and middleincome countries. Lancet. 2007;370(9592):1013-1015.

6. World alliance for patient safety the second global patient safety challenge safe surgery saves lives. http://www.who.int/patientsafety/ safesurgery/knowledge_base/SSSL_Brochure_finalJun08.pdf

7. Kushner AL, Cherian MN, Noel L, Spiegel DA, Groth S, Eti- enne C. Addressing the Millennium Development Goals from a surgical perspective: essential surgery and anesthesia in 8 low- and middleincome countries. Arch Surg. 2010;145:154-9.

8. Shillcutt SD, Sanders DL, Teresa Butron-Vila M, Kingsnorth AN. Costeffectiveness of inguinal hernia surgery in north- western Ecuador. World J Surg. 2013;37:32-41.

9. Ozgediz D, Jamison D, Cherian M, McQueen K. The burden of surgical conditions and access to surgical care in low- and middle-income countries. Bull World Health Organ. 2008;86:646-7.

10. PLoS Medicine Editors. A crucial role for surgery in reaching the UN millennium development goals. PLoS Med 2008;5:e182.

11. McQueen KA, Parmar P, Kene M, Broaddus S, Casey K, Chu K, et al. Burden of surgical disease: strategies to manage an existing public health emergency. Prehospital Disaster Med. 2009;24(Suppl 2):s22831.

12. Weiser TG, Regenbogen SE, Thompson KD, Haynes AB, Lipsitz SR, Berry WR, et al. An estimation of the global vol- ume of surgery: a modelling strategy based on available data. Lancet. 2008;372:139-44.

13. Dubowitz G, Detlefs S, McQueen KA. Global anesthesia workforce crisis: a preliminary survey revealing shortages contributing to undesirable outcomes and unsafe practices. World J Surg 2010;34:438-44.

14. Murray CJ, Vos T, Lozano R, Naghavi M, Flaxman AD, Michaud C, et al. Disability adjusted life years (DALYs) for 291 diseases and injuries in 21 regions, 1990-2010: a systematic analysis for the Global Burden of Disease Study 2010. Lancet. 2012;380:2197-223.

15. LeBrun DG, Chackungal S, Chao TE, Knowlton LM, Linden AF, Notrica $M R$, et al. Prioritizing essential surgery and safe anesthesia for the Post-2015 Development Agenda: Operative capacities of 78 district hospitals in 7 low- and middle-income countries. Surgery. 2014 Mar;155(3):365-73.

16. Martineau T, Subedi HN. Human Resources Capacity Assessment. Capacity Assessment for Health Systems Strengthening http:// www.nhssp.org.np/human_resources/Human Resources Capacity Assessment.pdf

17. Dixit H. Role of private sector for HRH (Human Resource for Health) production in Nepal. Journal of Ktm Medical College. 2013;2(4):97103. http://www.jkmc.com.np/issue/4/97-103.pdf

18. Annual Report. http://dohs.gov.np/wp-content/uploads/2014/04/ Annual_Report_2069_70.pdf. p74

19. Pandey A, Paudel P, Paudel L. Scenario of Health Camps in Nepal. J Nepal Health Res Counc. 2011April;9(18):86-8 http://www.jnhrc.com. np/index.php/jnhrc/article/view/263. 
20. Patn Academy of health Sciencs. http://www.pahs.edu.np/

21. Information Booklet On MBBS Program, Patan Academy of Health Sciences, School of Medicine (PAHS-SOM), Lalitpur. http://www. pahs.edu.np/wp-content/uploads/2010/02/pahs-mbbs-informationbooklet.pdf

22. Health Is Wealth: The Rise Of Private Hospitals In Nepal. http://www. newbusinessage.com/Sectoral/1964.
24. Annual report Department of Health Services 2070/71 (2013/14), Government of Nepal, Miinistry of Health and Population, Department of Health Services, Teku, Kathmandu. http://dohs.gov. np/wp-content/uploads/2014/04/Annual_Report_2070_71.pdf

25. Magar A, Subba K. Strengthening District Health Care System through Partnership with Academic Institutions: The Social Accountability of Medical Colleges in Nepal. J Nepal Med assoc. 2012;52(187):142-7.

23. Nepal Medical Council. http://www.nmc.org.np/ 